\title{
Benzeno: reflexos sobre a saúde pública, presença ambiental e indicadores biológicos utilizados para a determinação da exposição
} Benzene: reflections on public health, environmental presence and biological indicators used for the determination of exposure

\author{
Cristiane Barata-Silva ${ }^{1}$, Simone Mitri², Thelma Pavesi ${ }^{3}$, Enrico Saggioro ${ }^{4}$, \\ Josino Costa Moreira ${ }^{5}$
}

\begin{abstract}
Resumo
O uso indiscriminado de um número cada vez maior de substâncias químicas vem aumentando e a contaminação ambiental associada tem trazido sérias consequências para o sistema público de saúde devido à elevação de danos para a saúde humana. Uma das substâncias que desperta grande interesse devido à contaminação contemporânea é o benzeno, composto aromático classificado pela International Agency for Research on Cancer como reconhecidamente carcinogênico para humanos. O objetivo do presente estudo foi elaborar e discutir um panorama sobre a contaminação por benzeno, seu metabolismo, consequências para a saúde e sua determinação ambiental e biológica a partir de informações existentes na literatura científica. O levantamento de dados possibilitou o acesso a mais de 200 artigos científicos tanto de âmbito nacional quanto internacional, demonstrando a atualidade do tema e a necessidade de minimização da exposição humana a essa substância. A maioria preocupa-se em explorar o metabolismo e investigar indicadores de exposição, muitos já amplamente estudados e com sérias limitações. Contudo, um crescente número de pesquisadores estão empenhados em elucidar fatores relacionados à suscetibilidade e à interferência da exposição no material genético e proteico. Indicadores de exposição inovadores têm sido propostos com o objetivo de complementar as lacunas de informações anteriormente obtidas, contribuindo para o delineamento da estrutura da biologia de sistemas orgânicos frente à exposição ao benzeno
\end{abstract}

Palavras-chave: benzeno; exposição ambiental; toxicidade; indicadores biológicos.

\begin{abstract}
The indiscriminate use of an increasing number of chemicals is growing and associated environmental contamination has brought serious consequences for the public health system due to rising damage to human health. One of the substances that have attracted great interest due to contemporary contamination is benzene, aromatic compound classified by International Agency for Research on Cancer as a carcinogen known. The aim of this study was develop and discuss an overview of the
\end{abstract}

Trabalho realizado no Doutorado em Saúde Pública e Meio Ambiente da Escola Nacional de Saúde Pública Sérgio Arouca da Fundação Oswaldo Cruz (ENSP/ FIOCRUZ) - Rio de Janeiro (RJ), Brasil.

'Doutoranda em Saúde Pública e Meio Ambiente na ENSP/FIOCRUZ - Rio de Janeiro (RJ), Brasil.

${ }^{2}$ Mestre em Ciências da Saúde pela ENSP/FIOCRUZ; Tecnologista do Centro de Estudos da Saúde do Trabalhador e Ecologia Humana da Escola Nacional de Saúde Pública da Fundação Oswaldo Cruz - Rio de Janeiro (RJ), Brasil.

${ }^{3}$ Mestre em Química pela Universidade Estadual de Campinas (UNICAMP); Tecnologista do Centro de Estudos da Saúde do Trabalhador e Ecologia Humana da Escola Nacional de Saúde Pública da Fundação Oswaldo Cruz - Rio de Janeiro (RJ), Brasil.

${ }^{4}$ Doutor em Ciências da Saúde pela Escola Nacional de Saúde Pública Sérgio Arouca da Fundação Oswaldo Cruz; Professor de Toxicologia Clínica da Universidade Federal Fluminense (UFF) - Rio de Janeiro (RJ), Brasil.

${ }^{5}$ Doutor em Química pela Loughborough University; Pesquisador do Centro de Estudos da Saúde do Trabalhador e Ecologia Humana da Escola Nacional de Saúde Pública da Fundação Oswaldo Cruz - Rio de Janeiro (RJ), Brasil.

Endereço para correspondência: Cristiane Barata-Silva - Avenida Leopoldo Bulhões, 1480 - Manguinhos - CEP: 21401-210 - Rio de Janeiro (RJ), Brasil -

E-mail: cristianebarata@hotmail.com

Fonte de financiamento: nenhuma.

Conflito de interesse: nada a declarar 
contamination by benzene, its metabolism, health endings and their environmental and biological determination based on literature data existing. The survey provided access to more than 200 scientific papers, both nationally and internationally, demonstrating the relevance of the topic and the need to minimize human exposure to this substance. The majority is concerned with exploring the metabolism and investigates indicators of exposure, many already widely studied and with serious limitations. However, a growing number of researchers are committed to elucidate factors related to interference susceptibility and exposure on protein and genetic material. Indicators of innovative exhibition has been proposed with the aim of complementing gaps of information previously obtained, contributing to the design of the structure of the organ biology systems upon exposure to benzene.

Keywords: benzene; environmental exposure; toxicity; biological indicators.

\section{INTRODUÇÃO}

O número de substâncias químicas (xenobióticos) utilizadas em atividades domésticas e industriais, com as quais temos contato por meio das mais variadas vias, cresce continuamente, e o comprometimento da qualidade da saúde de uma população está diretamente relacionado com as relações sociais e o ambiente. Atualmente, pode-se afirmar que estes são delineados pelos processos produtivos adotados que distribuem possibilidades diferenciadas de exposição a agentes, cargas e riscos ${ }^{1}$. O avanço na frequência dessa exposição é um dos responsáveis pelo aumento de registros de patologias humanas atualmente observadas, ocupando posição de destaque na saúde pública, com consequentes reflexos sobre sistemas públicos de saúde 2 .

A contaminação dos diversos segmentos ambientais por esses xenobióticos consiste na principal via de exposição da população em geral, dada a sua presença no ar, alimentos, solo e água ${ }^{3-5}$. Desta forma, são necessários estudos específicos que proporcionem conhecimento das variáveis existentes em cada situação e permitam realizar avaliação completa dos riscos e prevenção dos agravos à saúde advindos dos ambientes contaminados ${ }^{3,6-8}$.

Uma das substâncias que requerem atenção dos pesquisadores devido à toxicidade e ampla presença é o benzeno, um hidrocarboneto aromático largamente utilizado como matéria-prima para diversos produtos, como detergentes, gasolina e plásticos ${ }^{9-13}$.

O objetivo deste trabalho foi avaliar abordagens dos diversos estudos cujo tema principal foi a exposição ao benzeno e seus diversos danos à saúde humana. Realizou-se compilação dos biomarcadores utilizados para a determinação da exposição e principais técnicas analíticas atualmente empregadas.

\section{METODOLOGIA}

Foram consultadas as bases de dados eletrônicas Medline, PubMed e Scielo, as quais têm ampla abrangência, possibilitando a inclusão de todos os artigos originais indexados retrospectivamente até o ano 1989, quando foram datados registros oficiais sobre o benzeno. Utilizou-se o termo de busca "benzeno" com exposição, metabolismo, câncer, DNA, suscetibilidade, leucemia, revisão, toxicidade, biomarcadores e legislação, além de suas versões em inglês. Contemplaram-se artigos tanto em inglês quanto em português, desde que disponibilizados eletronicamente na íntegra no portal de periódicos da Coordenação de Aperfeiçoamento de Pessoal de Nível Superior (CAPES). Ao fim das pesquisas em cada base, as referências duplicadas foram excluídas.

O processo de pesquisa foi realizado entre os anos $2013 \mathrm{e}$ 2014. Foram selecionados 224 artigos, qualificados, de acordo com os resumos, como possíveis candidatos a fornecer embasamentos técnico-científicos, segundo o conteúdo de caráter inédito, por meio de estudos observacionais (estudos de casocontrole e de coorte) ou que compilavam informações relevantes sobre $\mathrm{o}$ assunto em forma de revisões. Os trabalhos que não apresentavam a metodologia adotada para a obtenção dos resultados de forma clara e que não estava disponível na íntegra foram excluídos.

Os resumos foram compilados, analisados e classificados separadamente por dois pesquisadores como "fora do escopo" ou "dentro no escopo", de acordo com critérios de inclusão e exclusão estabelecidos e citados. Após a leitura completa de cada resumo, cerca de 150 artigos foram selecionados e utilizados como base teórica para a elaboração do presente trabalho.

\section{RESULTADOS E DISCUSSÃO}

\section{Benzeno e sua presença no ambiente}

O benzeno é uma das substâncias mais produzidas em quantidade e diversidade, presente na composição de óleos naturais, gasolina e fumaça de cigarros ${ }^{14,15}$. Por sua ação carcinogênica, exige maior controle e precaução, admitindo-se que para substâncias carcinogênicas e genotóxicas não há limite seguro de exposição ${ }^{16-18}$.

No passado, o benzeno teve ampla utilização, inclusive como loção pós-barba por seu aroma adocicado ${ }^{19}$. Foi adicionado 
à gasolina como aditivo, temporariamente substituído pelo chumbo tetraetila ${ }^{20}$ e retomado até agora ${ }^{21,22}$. No Brasil, a Agência Nacional de Petróleo, Gás Natural e Biocombustíveis (ANP), por meio da resolução ${ }^{\circ} 40$, de $25 / 10 / 2013$, determina o máximo de benzeno de $1 \%$ em volume, na gasolina do tipo C ou Premium tipo $\mathrm{C}^{23}$.

Em geral, a população está exposta ao benzeno pela inalação de ar contaminado. A sua presença na atmosfera vem sendo registrada em áreas industriais, ambientes urbanos e rurais, sendo ele considerado contaminante global ${ }^{3,24-27}$.

Os efeitos tóxicos sobre o organismo fizeram com que o benzeno tivesse sua concentração no ar de ambientes de trabalho, ou mesmo na atmosfera, regulada em diversos países, minimizando a exposição crônica. A União Europeia ${ }^{28}$ definiu como limite para a exposição ocupacional o valor de $1 \mathrm{mg} \mathrm{dm}^{-3} \mathrm{e}$ a American Conference of Governmental Industrial Hygienists (ACGIH) estabeleceu que o limite de Threshold limit value Time weighted average (TLV-TWA) era $0,5 \mathrm{mg} \mathrm{dm}^{-3}$ (média ponderada por 8 horas de exposição) ${ }^{29}$.

A concentração atmosférica desse contaminante varia conforme a localização das fontes emissoras. Assim, locais próximos ou com aglomeração de várias fontes, tanto pontuais quanto difusas, apresentam concentrações mais elevadas ${ }^{30-32}$, superiores a $10 \mathrm{mg} / \mathrm{dm}^{3}$. Moradores que residem ou trabalham no entorno de indústrias químicas, postos de gasolinas, oficinas mecânicas e de exploração petrolífera estarão sujeitos à exposição ambiental mais elevada deste xenobiótico do que a recomendada pelos órgãos regulamentadores ${ }^{26,33}$.

Além da contaminação atmosférica, há estudos que descrevem a existência da contaminação de outros compartimentos ambientais, como água e solo, por vazamentos oriundos de tanques das indústrias petroquímicas e de postos de armazenamento e distribuição de combustíveis. Brito et al. relataram que em 2005 o Brasil havia registrado cerca de 30.000 postos de combustíveis, dos quais 20 a $30 \%$ possuíam pequenos e contínuos vazamentos em virtude do envelhecimento dos taques de estocagem. Essa falha atinge principalmente a população que reside próximo a eles e muitas vezes consome água proveniente de poços artesianos ${ }^{34-37}$.

Essa fonte de contaminação é preocupante devido ao benzeno ser um hidrocarboneto monoaromático, possuindo ligeira solubilidade em água, o que possibilita a chegada deste xenobiótico com maior facilidade ao lençol freático ${ }^{35}$. O contato com o benzeno por via oral pode ocorrer de forma direta, pela ingestão de água contaminada, consumo de alimentos irrigados por ela ou que a utilizaram no preparo.

Contudo, a Agência de Proteção Ambiental Norte-americana (EPA) estabelece os limites máximos para a concentração de benzeno em $5 \mu \mathrm{g} / \mathrm{L}$ para água potável ${ }^{38}$. No Brasil, a portaria ${ }^{\circ}$ 2914, de 12 de dezembro de 2011, segue o mesmo valor para os limites máximos permitidos em água classificada como potável $^{39}$. O Conselho Nacional do Meio Ambiente (CONAMA), na resolução $n^{\circ} 396$, de 3 de abril de $2008^{40}$, estabelece que o valor máximo de benzeno permitido em água subterrânea para consumo é $5 \mu \mathrm{g} / \mathrm{L}$ e para recreação, $10 \mu \mathrm{g} / \mathrm{L}$. Estes limites máximos de valores de concentração permitem que os riscos potenciais de exposição ao benzeno sejam minimizados.

\section{Exposição ao benzeno no Brasil}

No Brasil, a preocupação com exposição de grupos populacionais ao benzeno teve início com denúncias pelo Sindicato dos Metalúrgicos de Santos (SP), na década de 1980, de casos de leucopenia em trabalhadores da Companhia Siderúrgica Paulista (COSIPA), em Cubatão ${ }^{41}$.

As principais fontes produtivas de benzeno no Brasil estão concentradas nos centros de produção petroquímica e refino de petróleo, responsáveis por aproximadamente $95 \%$ da produção nacional ${ }^{42}$.

Em 1993 foi realizado, em Belo Horizonte, o "Seminário Nacional sobre Exposição ao Benzeno e outros Mielotóxicos”, que posteriormente resultou na revisão da Norma Regulamentadora do Trabalho (NR) $n^{\circ} 15$, em seu tópico relativo ao benzeno ${ }^{43}$.

No ano seguinte, uma Comissão Tripartite (portaria 10 de 8 de setembro de 1994) da qual participavam representantes dos Ministérios do Trabalho, Saúde e Previdência Social, dosEmpregadores e dos Trabalhadores criou a Comissão Nacional Permanente do Benzeno, e em 28 de setembro de 1995 foi pactuado o Acordo sobre o Benzeno ${ }^{44,45}$. Também ficou definido que a Valor de Referência Tecnológico ponderada pelo tempo (VRT-MTP), que é calculado pela concentração média ponderada pelo tempo, medida na zona respiratória, para jornada de 8 horas, fosse estabelecida em $2,5 \mathrm{ppm}$ para siderúrgicas e 1,0 ppm para outras indústrias.

De acordo com Norma Técnica do Ministério da Saúde de 2006, a análise dos riscos relacionados a agentes químicos é atividade prioritária para qualificar intervenção na vigilância em saúde, e reconhece que a complexidade desta atividade não deve se restringir meramente a uma determinação da concentração ambiental à qual a população está exposta ${ }^{46}$.

Estudos científicos relacionados ao benzeno, desenvolvidos em âmbito nacional a partir do ano 2000, evidenciam a crescente preocupação com exposição e possíveis consequências para a população em geral. Esta coletânea de trabalhos compreende desde a avaliação ambiental utilizando como matriz o $\operatorname{ar}^{47-49}$, ou a água e alimentos ${ }^{21}$, à avaliação biológica dos biomarcadores em urina ${ }^{16,50-54}$ e sangue $e^{55}$. Outros trabalhos foram direcionados para a verificação da suscetibilidade da população por meio de um estudo de polimorfismo ${ }^{56,57}$ e avaliação dos efeitos genotóxicos associados à exposição ao benzeno ${ }^{58-61}$ e os demais desfechos ${ }^{62,63}$. 
Vias de exposição, metabolização e efeitos sobre a saúde

As principais formas de introdução do benzeno no organismo são as vias respiratória (vapores) e oral (alimentos e água). A via cutânea é mais rara, sendo necessário contato dérmico com essa substância na forma líquida, porém, quando ocorre, possui alto índice de absorção ${ }^{33}$. Em termos de saúde pública, a via de contaminação com maior relevância é a respiratória e a maior parte do benzeno inalado é eliminada pela expiração, ficando a parte que é absorvida acumulada principalmente em tecidos com alto teor lipídico ${ }^{64}$. Após a absorção, a metabolização do benzeno ocorre preferencialmente no fígado, conforme representado nas Figuras 1 e 2. No processo de excreção dos metabólitos gerados, o rim é o principal responsável por tal função ${ }^{26}$.

A primeira etapa do metabolismo envolve participação de enzimas da família do citocromo P450 2E1 (CYP2E1), levando à formação de um intermediário eletrofílico reativo ${ }^{65-68}$, o óxido de benzeno (BO), que possui tempo de meia-vida in vivo estimado em 7,9 minutos ${ }^{15,69}$. Esse metabólito tem a capacidade de se ligar covalentemente com sítios nucleofílicos de proteínas e DNA ${ }^{65}$ e pode sofrer nova metabolização, gerando novos metabólitos reativos (muconaldeídos e benzoquinonas), que ainda detêm a capacidade de ligação ao DNA e às proteínas ${ }^{65}$.
Também promove aumento na formação de espécies reativas de oxigênio (EROs) que comprometem o sistema antioxidante, gerando estresse oxidativo ${ }^{60,70-72}$. Os adutos formados nas reações entre óxido de benzeno e macromoléculas (proteínas ou DNA) $)^{15,73,74}$ são considerados pré-cancerígenos ${ }^{75-77}$.

O óxido de benzeno espontaneamente se transforma em fenol in vivo, metabolizado posteriormente com participação da CYP2E1, à hidroquinona considerada precursora de metabólitos mielotóxicos ${ }^{78}$. As benzoquinonas também são capazes de formar adutos de DNA em sistemas celulares e humanos ${ }^{13}$. Esses adutos podem gerar desde mutações proto-oncogenes ou formação de genes supressores de tumor à iniciação de processos de carcinogênese química ${ }^{79}$, como exemplificado na Figura 3.

Suspeita-se que na presença concomitante do fenol e hidroquinona no organismo ocorra interação farmacocinética, resultando em aumento na toxicidade dos metabólitos e diminuição das células da medula óssea de camundongos ${ }^{80}$. A presença da hidroquinona no organismo pode promover a inibição da ribonucleotídio redutase, uma enzina essencial para a síntese de DNA ${ }^{69}$.

Os adutos produzidos por reações desses metabolitos reativos com albumina, hemoglobina ou com DNA têm sido utilizados

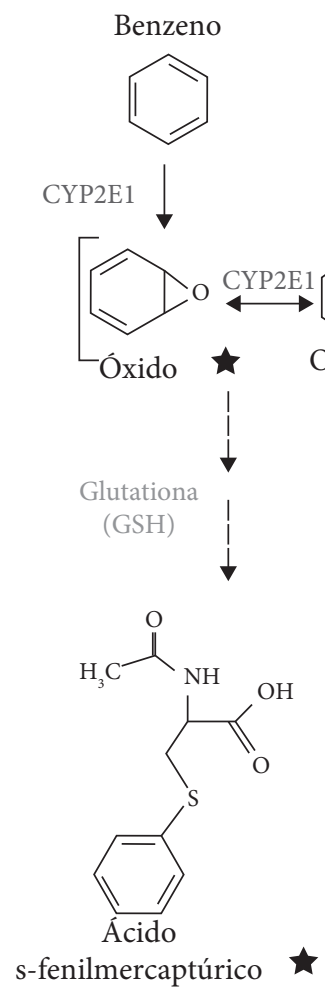

Utilizados como biomarcadores

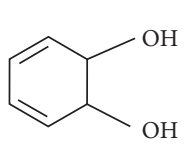

Diidrodiol

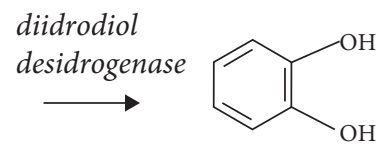

Catecol<smiles>[14CH3][14CH3]</smiles>

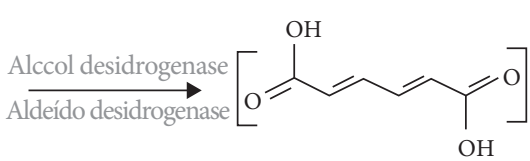

Ácido trans,trans-mucônico
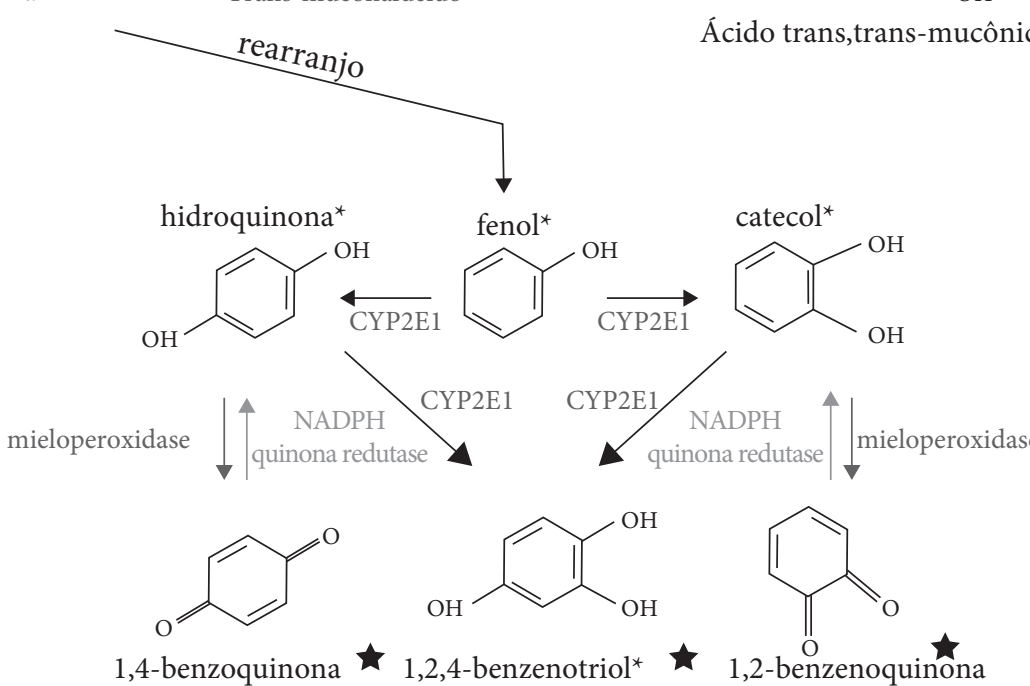

1,4-benzoquinona

1,2,4-benzenotriol*

1,2-benzenoquinona 
para avaliação da exposição e relacionados com efeitos tardios à saúde, como o desenvolvimento da leucemia ${ }^{15,73,81-83}$.

$\mathrm{O}$ aduto S-(2-hidroxiciclohexa-3,5-dien-1-ila) cisteína da albumina, por exemplo, pode ser detectado no sangue até um mês após a sua formação, e quando a proteína é a hemoglobina, até quatro meses. Apesar de menor estabilidade in vivo, o aduto formado com albumina é geralmente preferido como biomarcador quando a exposição é curta, visto ser mais abundante que aquele formado com hemoglobina ${ }^{84}$, e se acumula ao longo de três a quatro semanas ${ }^{73}$. $\mathrm{O}$ aduto produzido na ligação do óxido de benzeno à albumina (BO-Alb), outro potencial biomarcador, tem tempo de meia-vida de 21 dias, limitando a sua utilização como aqueles formados pelas benzoquinonas ${ }^{15}$.

Devido à participação de várias enzimas nas rotas metabólicas do benzeno, diferenças genéticas podem alterar sua eficiência, com consequente aumento ou diminuição da concentração de metabólitos toxicologicamente relevantes. Estudos indicam que os polimorfismos das glutationa $S$-transferase (GSTT1, GSTM1) e citocromos P450 (CYP2E1) têm grande importância neste processo $\mathrm{o}^{26,85-88} \mathrm{e}$, sendo características individuais, estas variações devem ser consideradas nas avaliações dos impactos potenciais sobre a saúde de grupos populacionais.

Além da determinação dos adutos, outros indicadores utilizados na avaliação da exposição, como o ácido trans, trans-mucônico (ttAM) e o ácido S-fenilmercaptúrico (S-PMA), metabólitos alifáticos eliminados pela urina ${ }^{33}$. A avaliação biológica em diferentes matrizes usualmente utiliza biomarcadores distintos, como o próprio benzeno no ar expirado, o ttAM ou o S-PMA na urina e adutos de DNA ou de proteína no sangue $e^{89-91}$.

Os fatores limitantes para a determinação da escolha do bioindicador a ser utilizado na avaliação biológica são o tempo

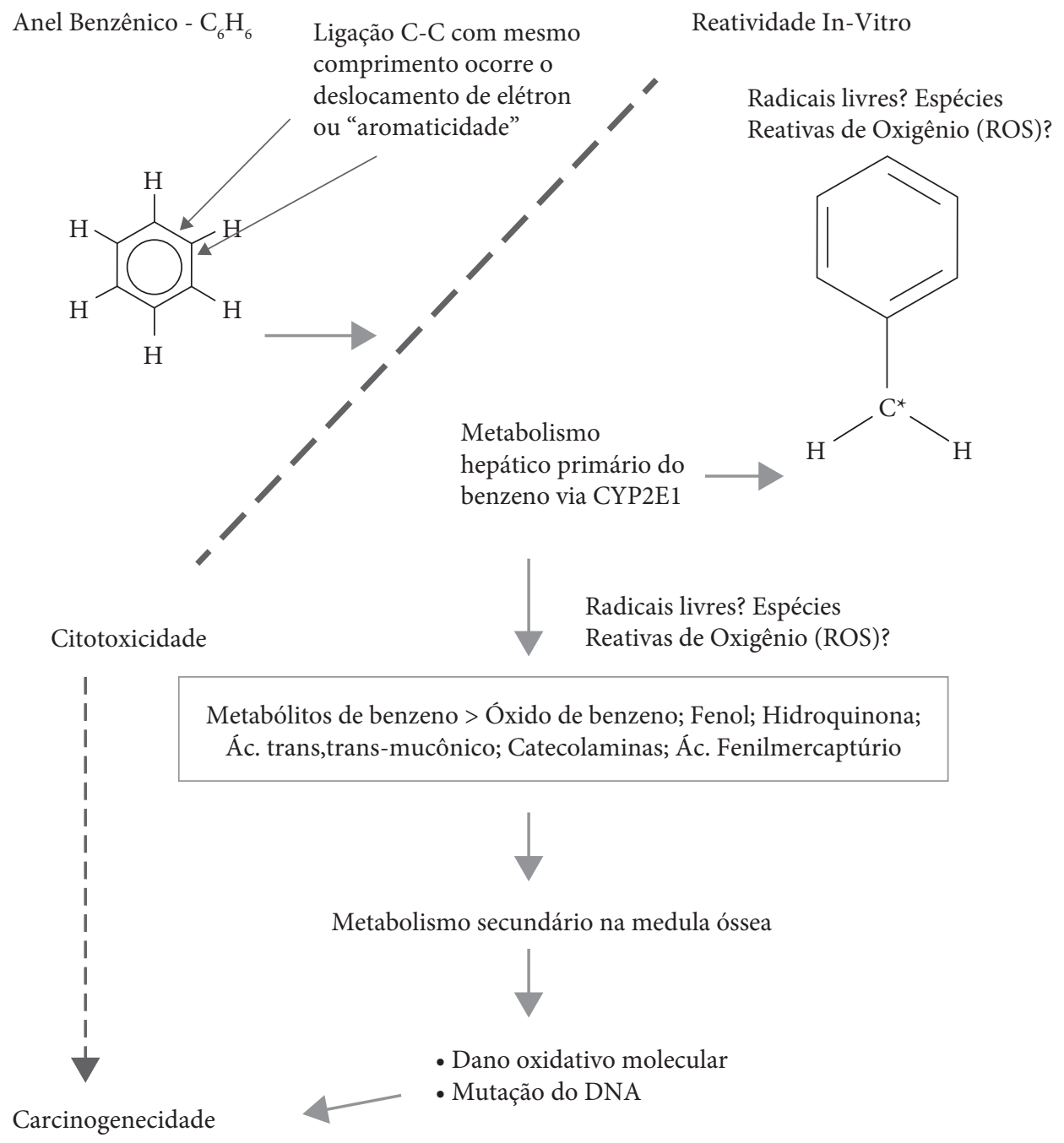




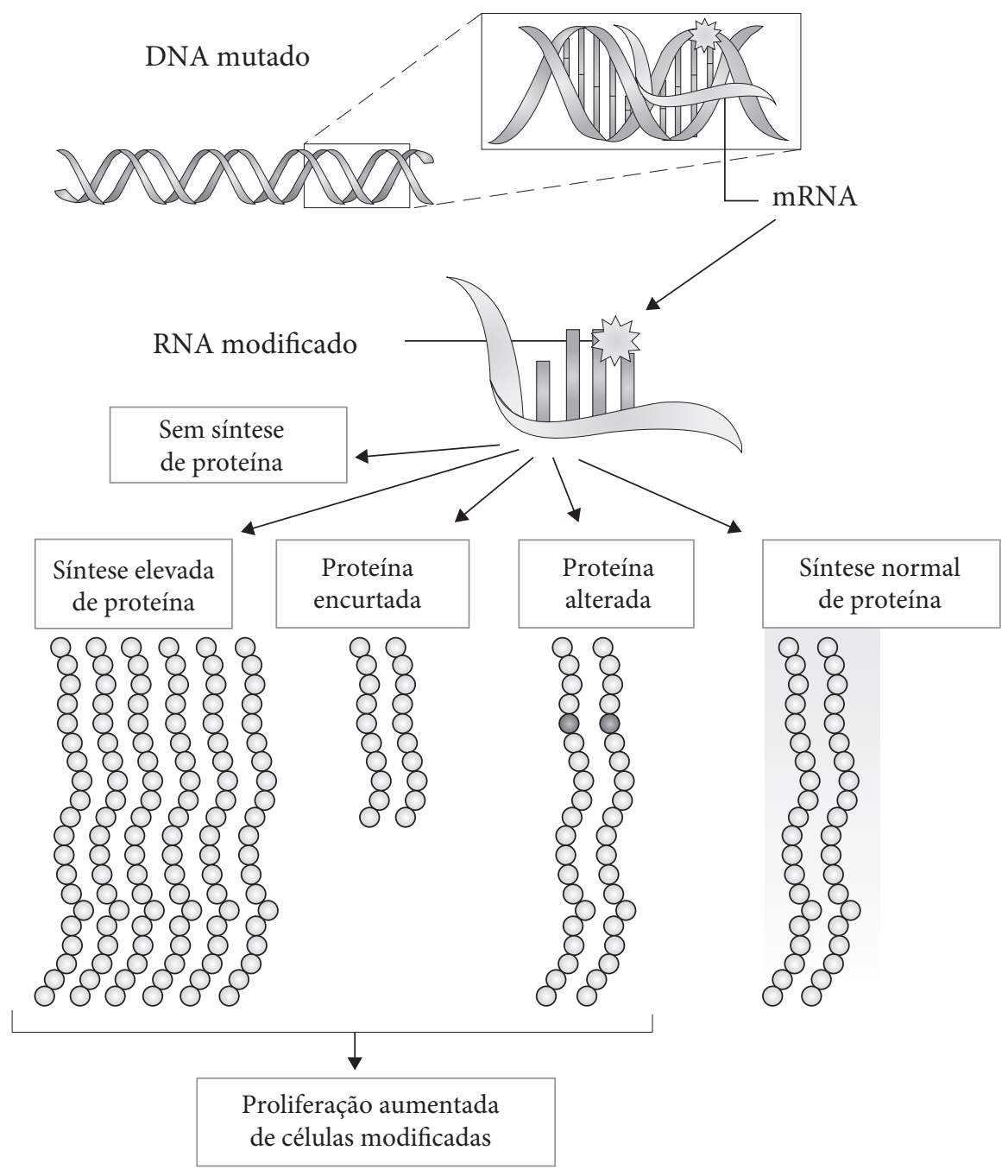

Adaptado de Buthbumrung et al. ${ }^{76}$

Figura 3. Representação esquemática da síntese de proteína a partir do DNA ligado a um carcinógeno (estrela vermelha). A mutação ocorrida no DNA gera um RNA modificado, que posteriormente é traduzido em proteína modificada. Essa pode resultar em uma expressão aumentada ou diminuída da proteína ou em uma síntese de proteína modificada, com a possibilidade de levar a uma proliferação exacerbada de células modificadas e, consequentemente, ao desenvolvimento do tumor

de permanência no organismo após a exposição, a sensibilidade de cada um frente à exposição a baixas concentrações ${ }^{33,92,93} \mathrm{e}$ disponibilidade instrumental. A avaliação biológica deve considerar informações a respeito da coleta do material a ser analisado, como o momento da coleta ${ }^{6}$.

Rappaport et al. ${ }^{25}$ apresentaram o conceito de que o metabolismo do benzeno ocorre por duas vias, ainda sem a clareza de todo o mecanismo envolvido. Outros estudos observaram que a curva da dose específica relacionada à formação dos metabólitos totais frente à exposição de altas concentrações de benzeno ( $>1 \mathrm{ppm}$ ) atinge um platô justificado por saturação no metabolismo, o que inviabiliza a relação direta da formação de metabólitos com a dose de benzeno que o indivíduo está exposto ${ }^{13,94}$.
A exposição crônica a baixas concentrações de benzeno está associada a enfermidades como anemia aplástica e leucemia $^{10,95-97}$. Há também estudos que sugerem que tal exposição em diferentes concentrações podem aumentar o risco de desenvolver linfoma não-Hodgkin ${ }^{14,95,98-100}$, mieloma múltiplo ${ }^{95,98,101} \mathrm{e}$ várias outras desordens hematopoiéticas. Encontram-se relatos de que a exposição média de oito a nove horas por dia por um longo período induz a alterações de cromossomas anormais que levam à má formação do feto ou até mesmo à infertilidade do homem ${ }^{102-104}$.

Outros efeitos resultantes da exposição aguda são dor de cabeça, fadiga, tontura, irritação das mucosas, convulsões, excitação, depressão e, eventualmente, morte por falência respiratória ${ }^{105,106}$. A medula óssea é o principal órgão alvo de sua toxicidade ${ }^{4,107}$. 


\section{Avaliação ambiental}

Rejeitos contendo benzeno, bem como os responsáveis por sua remoção e/ou biodegradação, são responsáveis pelas concentrações encontradas nos diversos tipos de ambientes (urbano, rural e indoor). Sua permanência na atmosfera é limitada por reações com radicais hidroxilas $(\cdot \mathrm{OH})$, que fazem com que esse tempo seja de apenas algumas horas ou dias ${ }^{108}$. Entretanto, habitações situadas na vizinhança de indústrias ou outros locais onde se utiliza o benzeno sob a forma pura ou não, constituem situações preocupantes para a contaminação da população residente. O solo e as águas também podem ser contaminados por rejeitos industriais e vazamento de tanques de gasolina ${ }^{33,109-111}$.

Para controle de benzeno na atmosfera, a ACGIH adota como controle para exposição os seguintes parâmetros e valores: média ponderada pelo tempo para 40 horas de exposição (time-weighted average - TWA) de 0,5 ppm; e concentração máxima (short-term exposure level - STEL/Teto) de 2,5 ppm ${ }^{29}$.

\section{Avaliação biológica}

A avaliação biológica é um instrumento importante na determinação da seriedade ou não da contaminação. Para isto se usa a comparação com o Valor de Referência da Normalidade, que no Brasil é definido pela NR-7 do Ministério do Trabalho e Emprego, como o valor do agente químico ou de seus metabólitos possíveis de serem encontrados em populações não ocupacionalmente expostas ${ }^{112}$.

A Associação Brasileira de Higienistas Ocupacionais ratifica os valores de referência adotados pela ACGIH, que prescreve como indicadores da exposição ocupacional ao benzeno a determinação dos ácidos S-PMA e t,t-mucônico, ambos a partir de amostra de urina coletada ao final da jornada de trabalho, e estabelece como Indicador Biológico de Exposição (BEI) os valores $25 \mu \mathrm{g} / \mathrm{g}$ de creatinina e $500 \mu \mathrm{g} / \mathrm{g}$ de creatinina respectivamente ${ }^{29}$.

Em linhas gerais, a avaliação biológica permite o diagnóstico dos desvios das condições padrões do ambiente; a avaliação dos hábitos próprios de cada indivíduo; a estimativa da dose absorvida, evidenciando melhor os efeitos sobre a saúde do que a concentração ambiental; a identificação de outras vias de absorção, como a cutânea; e o acompanhamento das diferenças individuais que tornam algumas pessoas mais vulneráveis a determinados compostos químicos, seja devido a fatores endógenos (constituição genética, antropométricos, estado de saúde) e/ou exógenos (hábito de fumar, dieta alimentar, coexposição) $)^{93}$.

\section{Ácido trans,trans-mucônico}

Por meio da portaria n ${ }^{\circ} 34$, de 20 de dezembro de 2001, do Ministério do Trabalho e Emprego ${ }^{113}$ ficou estabelecido que a monitorização da exposição ao benzeno deve ser realizada através da determinação da concentração do $t t A M$ presente na urina ${ }^{114,115}$ e tem valor limite urinário de $500 \mu \mathrm{g} / \mathrm{g}$ de creatinina ${ }^{29}$. Segundo o estudo realizado por Coutrim et al. ${ }^{16}$, a concentração máxima deste metabólito no organismo ocorre 5,1 horas após uma jornada de trabalho (6 a 8 horas), sendo apenas $3,9 \%$ do benzeno absorvido excretado sob tal forma na urina ${ }^{16}$.

$\mathrm{O} t t A M$ é um indicador sensível à exposição mesmo às baixas concentrações ambientais. No entanto, a utilização deste ácido como indicador biológico apresenta certa fragilidade, uma vez que já é conhecido uma série de interferentes que fazem os valores destes aumentar ${ }^{116-118}$, como a ingestão de ácido sórbico e seus sais, muito utilizados na indústria alimentícia ${ }^{119,120}$, e de bebida alcoólica ${ }^{121}$, o tabagismo ${ }^{6,122}$, ou a exposição simultânea ao tolueno ${ }^{123,124} \mathrm{e}$ aos hidrocarbonetos policíclicos aromáticos (HPAs) ${ }^{16,125}$.

Existem diversas técnicas preconizadas para a determinação do $t t A M$, como a cromatografia gasosa com detecção por espectrometria de massas (CG-MS) ou por ionização em chama (CG-FID), a eletroforese capilar e a cromatografia líquida de alta eficiência com detecção por absorção no UV (HPLC-UV) ou espectrometria de massas (HPLC-MS) ou espectrometria de massas sequencial (HPLC-MS/MS) ${ }^{115-127}$. As duas primeiras técnicas supracitadas têm como desvantagem a necessidade de uma etapa de derivatização, que é um procedimento dispendioso, demorado e com rendimento variável ${ }^{115}$.

Entretanto, uma grande limitação ao uso do ttAM como indicador biológico de exposição se deve ao fato de que exposições a baixa concentração de benzeno podem gerar variação no nível deste metabólito na urina por conta de diferenças individuais no metabolismo do benzeno que fazem com que a curva dose/resposta não seja linear ${ }^{16}$.

\section{Ácido S-fenilmercaptúrico}

Assim como o ttAM, o ácido S-PMA é um metabólito alifático excretado pela urina, sendo que apenas $0,11 \%$ do benzeno absorvido é biotransformado neste produto. O tempo de meia-vida de eliminação é de aproximadamente 10 horas, o que o torna um forte candidato a biomarcador de exposição devido ao fato de ter permanência maior quando comparado ao $t t A M$ no organismo. O seu nível na urina não sofre interferência da dieta, porém, assim como o $t t A M$, o hábito de fumar atua como fator de confundimento nas análises do S-PMA, cujo valor limite urinário é de $25 \mu \mathrm{g} / \mathrm{g}$ de creatinina ${ }^{29}$.

O método empregado para a determinação do S-PMA deve ter eficiência o suficiente para detectar pequenas variações nos níveis urinários, uma vez que este metabólito encontra-se em baixas concentrações. 
As técnicas descritas para a sua determinação são o Enzyme Linked Immuno Sorbent Assay (ELISA), a cromatografia gasosa com detecção por espectrometria de massas (CG-MS) ou por captura de elétron (GC-ECD) ou por fluorescência, e a cromatografia líquida de alta eficiência, com detecção por espectroscopia de absorção UV (HPLC-UV) ou por fluorescência, ou espectrometria de massas (HPLC-MS) ou espectrometria de massas sequencial (HPLC-MS/MS) ${ }^{6,16,128-131}$. Assim como na análise do $t t \mathrm{AM}$, a técnica que emprega a cromatografia gasosa necessita que haja uma etapa prévia de derivatização, que, como já citado anteriormente, é um procedimento dispendioso e com rendimento variável. Além disso, há a necessidade de uso do diazometano, classificado como substância carcinogênica ${ }^{115,128}$.

É importante ressaltar que os indicadores descritos nas distintas matrizes devem ser entendidos como um valor útil para a prevenção de possíveis enfermidades, porém não expressam a certeza da ocorrência de um desfecho mesmo com o indivíduo exposto a altas concentrações de benzeno. Tal acontecimento se justifica pela complexidade e variabilidade orgânicas de cada indivíduo e pelo tipo de exposição ao qual está submetido.

Entretanto, a relação entre os dados obtidos pelas medidas desses indicadores de dose interna e os efeitos sobre a saúde não é direta, uma vez que vários fatores genéticos e ambientais interferem nesse processo. Alguns deles, como o polimorfismo enzimático, já foram discutidos anteriormente.

Os adutos formados com DNA, hemoglobina ou albumina têm sido utilizados atualmente como biomarcadores da dose efetiva ${ }^{60,82,132}$. Dentre estes, os adutos de proteínas podem ser considerados os que expressam mais fidedignamente a relação entre a exposição e o dano por ela causado, devido ao fato do organismo não ter capacidade de reparar esta alteração (dano irreversível). Ao contrário, para o aduto de DNA o organismo possui sistemas de reparação que restauram a estrutura do DNA, como representado na Figura 4. Além disso, os adutos formados com proteínas são muito mais abundantes do que os formados com o DNA, isto é, cada $1 \mathrm{~mL}$ de sangue contém cerca de $150 \mathrm{mg}$ de hemoglobina, $30 \mathrm{mg}$ de albumina, que está presente no soro, e 0,003 a $0,008 \mathrm{mg}$ de $\mathrm{DNA}^{74}$.

\section{Adutos de DNA}

Na deteç̧ão e quantificação dos adutos de DNA, as técnicas atualmente utilizadas são os imunoensaios, a marcação com fósforo radioativo ( ${ }^{32} \mathrm{P}$ - Postlabelling) e a cromatografia líquida de alta eficiência acoplada a detectores de massa sequenciais (HPLC/MS/MS) ${ }^{81}$.
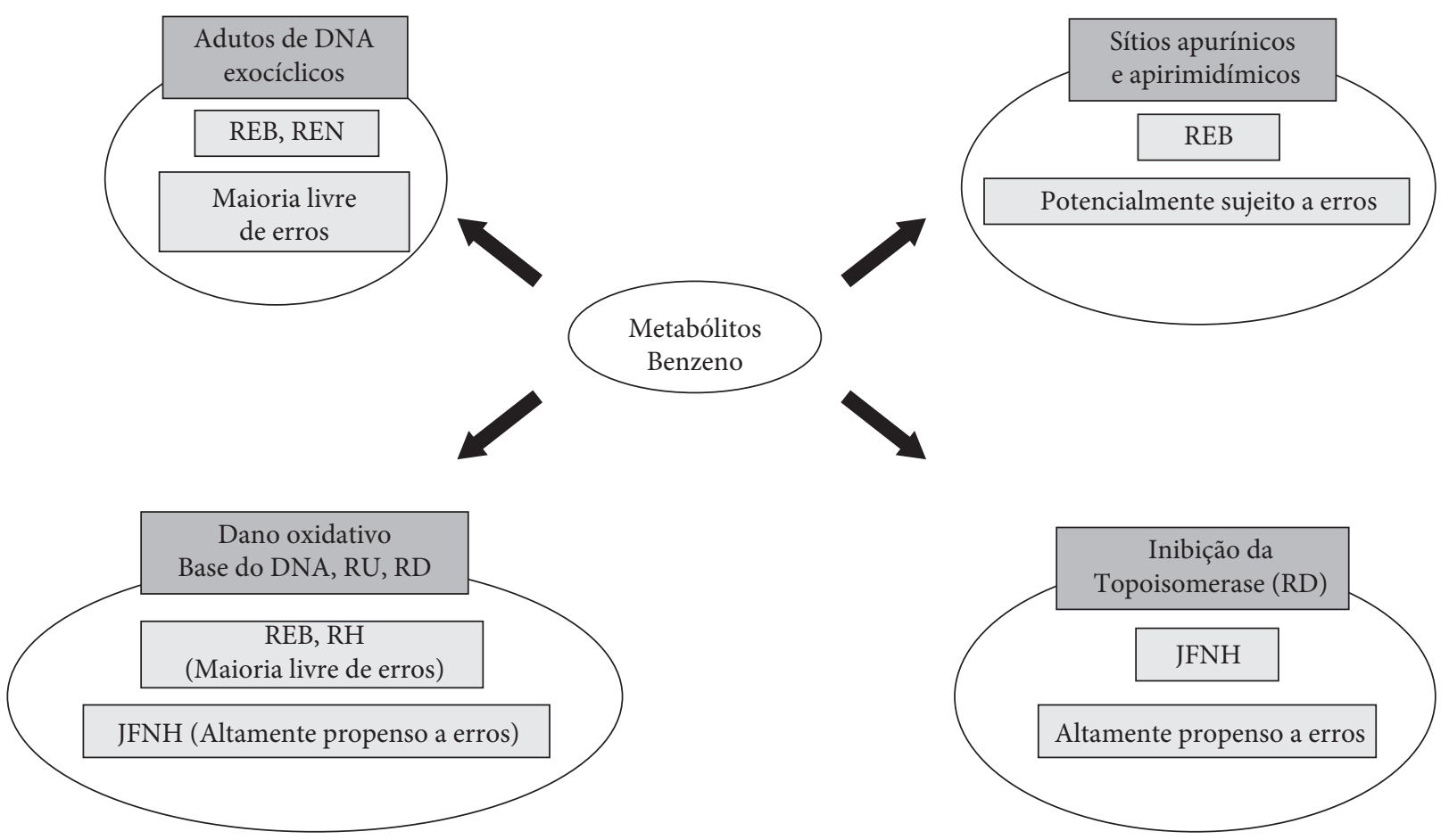

Adaptado de Hartwig ${ }^{137}$

REB: reparo por excisão de bases; REN: reparo por excisão de nucleotídeos; RU: ruptura de filamento único de DNA; RD: ruptura de duplofilamento de DNA; $\mathrm{RH}$ : recombinação homóloga; JFNH: junção dos não homólogos

Figura 4. Sistemas de reparação do DNA envolvidos na remoção das alterações induzidas por metabólitos do benzeno 
Os imunoensaios utilizam anticorpos retidos em uma placa capazes de reconhecer e se ligar aos adutos de DNA ou ao DNA modificado presentes em fluidos biológicos. Dependo do tipo de ligante utilizado, quando ocorre a ligação, alguns emitem luminescência e outros promovem a mudança na coloração, que pode ser visualizada pela observação da absorvância da luz emitida por um espectrofotômetro. Porém, a ligação que deveria ser específica para cada estrutura de aduto pode ocorrer com estruturas semelhantes, levando a interpretações equivocadas dos resultados, sendo esta uma das principais limitações dessa técnica ${ }^{76}$.

Outra técnica utilizada é a imuno-histoquímica, que permite a visualização de danos no DNA em amostras de tecidos parafinados, caso os adutos formados sejam quimicamente estáveis. Os adutos são semiquantificados por sistemas computacionais acoplados à microscopia eletrônica ${ }^{76}$.

Tais técnicas têm como vantagens: ótima sensibilidade; quantificação por curva de calibração; permitem a "localização" dos adutos e o uso de amostras de tecido humano; e possibilitam analisar elevado número de amostras com boa relação custo-benefício. Como desvantagens é possível descrever: a reação cruzada dos anticorpos com adutos similares; baixa especificidade; necessidade de número elevado de controles; e o fato de ser uma análise semiquantitativa ${ }^{76}$. Os imunoensaios são capazes de detectar 1 aduto a cada $10^{8}$ nucleotídeos analisados em uma alíquota de 1 a $100 \mu \mathrm{g}$ de $\mathrm{DNA}^{133}$.

A técnica da marcação com fósforo radioativo $\left({ }^{32} \mathrm{P}-\right.$ Postlabelling) é uma análise qualitativa que consiste na hidrólise enzimática do DNA com a nuclease micrococalfosfodiesterase, uma endo-exonuclease que digere preferencialmente ácidos nucleicos de cadeia simples. Em seguida, essa mistura passa pelo processo de separação pela cromatografia líquida de alta resolução (HPLC) e a fração de interesse é identificada e recolhida. Esta fração na presença da nuclease P1 ou butanol promove a formação dos $3^{\prime}$-nucleosídeos monofosfatos, que, em contato com a $\left[\gamma^{-32} \mathrm{P}\right]-\mathrm{ATP}$, geram o produto denominado $5^{\prime}$ - ${ }^{32} \mathrm{P}$-desoxirribonucleosídeos-3',5' -bifosfato, identificado pela cromatografia em camada delgada. Esta técnica possui alta sensibilidade e não requer equipamento de elevado custo. Porém, a estrutura molecular do aduto não é identificada, além de utilizar material radioativo durante o processo, que é relativamente dispendioso ${ }^{134}$. A técnica de ${ }^{32} \mathrm{P}$ - Postlabelling permite a detecção de 1 aduto a cada $10^{9}$ a $10^{10}$ nucleotídeos analisados em uma alíquota de 1 a $10 \mu \mathrm{g}$ de DNA, sendo considerada de excelente sensibilidade ${ }^{133}$.

A MS, em conjunto com a separação cromatográfica, seja líquida ou gasosa (LC ou GC), é uma técnica analítica de grande importância para a identificação e quantificação de adutos de DNA presentes em uma amostra. Ela fornece o tempo de retenção, a relação massa/carga $(\mathrm{m} / \mathrm{z})$ e informações sobre a abundância dos íons da fragmentação das substâncias que são comparados com uma coleção de informações contidas na biblioteca do software ou com o padrão isotópico, que é um conjunto das abundâncias relativas dos diferentes isótopos de um elemento químico adicionado durante o preparo da amostra $^{135}$. Esta técnica possui ótima sensibilidade, porém requer equipamento de alto custo e técnicos com habilidades para o seu manuseio e interpretação dos resultados gerados ${ }^{76}$.

A MS sequencial com ionização do tipo eletrospray e detector do tipo triplo quadrupolo tem capacidade de detectar 1 aduto a cada $10^{7}$ a $10^{8}$ nucleotídeos analisados em uma alíquota de 10 a $100 \mu \mathrm{g}$ de DNA, o mesmo observado pela análise por cromatografia líquida de alta eficiência (HPLC) com detecção eletroquímica ou fluorescência ${ }^{133}$.

\section{Adutos de proteína}

Para a detecção e quantificação dos adutos de proteína, a técnica mais comumente empregada é a cromatografia gasosa ou líquida acoplada à espectrometria de massa, sendo o princípio o mesmo descrito para o aduto de DNA, no qual o tempo de retenção, a relação massa/carga $(\mathrm{m} / \mathrm{z})$ e informações sobre a abundância dos íons da fragmentação das substâncias são comparados a uma coleção de informações contida na biblioteca do software ou com o padrão isotópico adicionado durante o preparo da amostra para a elucidação do aduto presente na amostra ${ }^{135}$.

As técnicas cromatográficas, principalmente a HPLC/ MS/MS, têm sido atualmente as que têm demonstrado maior avanço, ampliando consideravelmente as suas aplicabilidades na determinação de adutos.

\section{CONCLUSÃO}

As legislações atuais mostram grande preocupação com a exposição ambiental ou ocupacional ao benzeno e apresentam tendência de restringir cada vez mais os níveis permitidos de exposição, sendo um consenso à necessidade de substituir a utilização do benzeno a fim de erradicar a sua presença maciça nos aglomerados urbanos e rurais. Porém, a atual demanda de petróleo e de seus derivados dificulta essa tarefa.

Estudos desenvolvidos recentemente têm agregado novos achados e indicadores de suscetibilidade resultantes do maior conhecimento da toxicocinética e da toxicodinâmica do benzeno. Uma busca simplificada feita em uma única base de pesquisa, o PUBMED, utilizando como descritores os termos benzene exposure, benzene metabolism, benzene cancer, benzene DNA e benzene susceptibility resultou em cerca de 800 , 2.000, 500, 300 e 100 artigos publicados nos últimos cinco anos, 
respectivamente, sendo que cerca da metade deles reportam estudos em humanos.

Os dados demonstram a atualidade do tema, visto que ainda há muito a ser esclarecido tanto sob o ponto de vista clínico, quanto genético ou analítico. Por isso, as ações do benzeno sobre o organismo humano e seu controle têm sido explorados por um amplo número de pesquisadores voltados para a elucidação de cada etapa do metabolismo e, principalmente, para a suscetibilidade individual ao benzenismo. Em todos esses casos a necessidade de se conhecer mecanismos de advertência e de controle é fundamental.

Assim, a perspectiva futura das pesquisas científicas é desenvolver metodologias que utilizem indicadores ainda mais específicos ou que permitam identificar populações mais vulneráveis para, assim, minimizar a carga de exposição, prever e evitar os possíveis danos em saúde. Novos indicadores devem ser implementados com o objetivo de complementar as lacunas de informações existentes e contribuir para o entendimento mais aprofundado da biologia de sistemas do ser humano.

\section{AGRADECIMENTOS}

Este trabalho contou com o apoio financeiro da Fundação Oswaldo Cruz (FIOCRUZ), da Coordenação de Aperfeiçoamento de Pessoal de Nível Superior (CAPES) através do Programa "Brasil sem Miséria", do Conselho Nacional de Desenvolvimento Científico e Tecnológico (CNPq) e da Fundação de Amparo à Pesquisa do Estado do Rio de Janeiro (FAPERJ).

\section{REFERÊNCIAS}

1. Tambellini AT, Camara MV. A temática saúde e ambiente no processo de desenvolvimento do campo da saúde coletiva: aspectos históricos, conceituais e metodológicos. Ciênc Saúde Coletiva. 1998;3(2):47-59.

2. Araújo AEO. Avaliação da genotoxicidade dos gases derivados do petróleo em trabalhadores expostos ocupacionalmente em ambiente fechado [dissertação]. Brasília (DF): Universidade de Brasília. Faculdade de Medicina; 2008.

3. Arnold SM, Angerer J, Boogaard PJ, Hughes MF, O'Lone RB, Robison $\mathrm{SH}$, et al. The use of biomonitoring data in exposure and human health risk assessment: benzene case study. Crit Rev Toxicol. 2013;43(2):119-53.

4. Agency for Toxic Substances and Disease Registry. Toxicological profile for benzene. Atlanta, USA: Agency for Toxic Substances and Disease Registry; 2007.

5. Oga S. Fundamentos de toxicologia. São Paulo: Ed. Atheneu; 2005.

6. Weisel CP. Benzene exposure: an overview of monitoring methods and their findings. Chem Biol Interact. 2010;184(1-2):58-66.

7. Albertini R, Bird M, Doerrer N, Needham L, Robison S, Sheldon L, et al. The use of biomonitoring data in exposure and human health risk assessments. Environ Health Perspect. 2006;114(11):1755-62.

8. Zhang JJ, Lioy PJ. Human exposure assessment in air pollution systems. Scientific World Journal. 2002;2:497-513.

9. Cottica D, Grignani E. Evolution of technology and occupational exposures in petrochemical industry and in petroleum refining. G Ital Med Lav Ergon. 2013;35(4):236-43.

10. Sahmel J, Devlin K, Burns A, Ferracini T, Ground M, Paustenbach D. An analysis of workplace exposures to benzene over four decades at a petrochemical processing and manufacturing facility (1962-1999). J Toxicol Environ Health A. 2013;76(12):723-46.

11. Panko JM, Gaffney SH, Burns AM, Unice KM, Kreider ML, Booher LE, et al. Occupational exposure to benzene at the ExxonMobil refinery at Baton Rouge, Louisiana (1977-2005). J Occup Environ Hyg. 2009;6(9):517-29.
12. ACGIH. American Conference of Governmental Industrial Hygienists. TLV for benzene: CAS number: 71-43-2. Cincinnati, USA: American Conference of Governmental Industrial Hygienists; 2001.

13. Kim S. Benzene metabolism in humans: dose-dependent metabolism and interindividual variability [tese]. North Carolina, USA: University of North Carolina; 2006

14. Steinmaus C, Smith AH, Jones RM, Smith MT. Meta-analysis of benzene exposure and non-Hodgkin lymphoma: biases could mask an important association. Occup Environ Med. 2008;65(6):371-8.

15. Lin YS, Vermeulen R, Tsai CH, Waidyanatha S, Lan Q, Rothman N, et al. Albumin adducts of electrophilic benzene metabolites in benzene-exposed and control workers. Environ Health Perspect. 2007;115(1):28-34

16. Coutrim MX, Carvalho LRF, Arcuri ASA. Avaliação dos métodos analíticos para a determinação de metabólitos do benzeno como potenciais biomarcadores de exposição humana ao benzeno no ar. Quím Nova. 2000;23(5):653-63.

17. Scherer G, Ruppert T, Daube H, Kossien I, Riedel K, Tricker AR, Adlkofer F. Contribution of tobacco smoke to environmental benzene exposure in Germany. Enviroment Inernational.1995;21(6):779-89.

18. Johnson ES, Lucier G. Perspectives on risk assessment impact of recent reports on benzene. Am J Ind Med. 1992;21(5):749-57.

19. ECO-USA. Toxics. Químicos. Benzeno [Internet]. [cited 2014 Jan 31] Available from: http://www.eco-usa.net/toxics/quimicos-p/benzeno. shtml

20. Landrigan PJ. The worldwide problem of lead in petrol. Bull World Health Organ. 2002;80(10):768.

21. Santos MA, Távora BE, Koide S, Caldas ED. Human risk assessment of benzene after a gasoline station fuel leak. Rev Saúde Pública. 2013;47(2):335-44

22. Mielke HW, Laidlaw MA, Gonzales $\mathrm{C}$. Lead $(\mathrm{Pb})$ legacy from vehicle traffic in eight California urbanized areas: continuing influence of lead dust on children's health. Sci Total Environ. 2010;408(19):3965-75. 
23. ANP. Agência Nacional de Petróleo, Gás Natural e Biocombustíveis. Resolução ANP $n^{\circ}$ 40, de 25.10.2013. Diário Oficial da União 2013; 25 out.

24. Hu J, Ma H, Zhang W, Yu Z, Sheng G, Fu J. Effects of benzene and its metabolites on global DNA methylation in human normal hepatic L02 cells. Environ Toxicol. 2014;29(1):108-16.

25. Rappaport SM, Kim S, Lan Q, Vermeulen R, Waidyanatha S, Zhang L, et al. Evidence that humans metabolize benzene via two pathways. Environ Health Perspect. 2009;117(6):946-52.

26. Dougherty D, Garte S, Barchowsky A, Zmuda J, Taioli E. NQO1, MPO, CYP2E1, GSTT1 and GSTM1 polymorphisms and biological effects of benzene exposure - a literature review. Toxicol Lett. 2008;182(1-3):7-17.

27. Costa MAF, Costa MFB. Benzeno: uma questão de saúde pública. Interciencia. 2002;27(4):201-4.

28. Comissão Européia. Council Directive 97/42/EC of 27 June 1997 amending for the first time Directive 90/394/EEC on protecting workers from risks related to exposure to carcinogens at work [Sixth Individual Directive according to Art. 16(1) of Directive 89/391/EEC]. Official Journal of the European Communities No. L179, 08.07.1997. Brussels, Belgium: European Commission; 1997.

29. ACGIH. American Conference of Governmental Industrial Hygienists. Threshold Limit Values (TLVs) for chemical substances and physical agents biological exposure indices for 2013. Cincinnati, USA: ACGIH; 2013.

30. Tovalin-Ahumada H, Whitehead L. Personal exposures to volatile organic compounds among outdoor and indoor workers in two Mexican cities. Sci Total Environ. 2007;376(1-3):60-71.

31. Wallace L. Environmental exposure to benzene: an update. Environ Health Perspect. 1996;104(Suppl 6):1129-36.

32. IARC. International Agency for Research on Cancer. Benzene. Monograph Evaluation Carcinogenic Risk Chemical Human. 1989;45:159-218.

33. Johnson ES, Langard S, Lin YS. A critique of benzene exposure in the general population. Sci Total Environ. 2007;374(2-3):183- 98.

34. Brito FV, Oliveira AS, Neves HC, Azevedo JAT, Bhering DL, Reis SM, et al. Estudo da contaminação de águas subterrâneas por BTEX oriundas de postos de distribuição no Brasil. In: $3^{\circ}$ Congresso Brasileiro de P\&D em Petróleo e Gás; 2005; Brasil.

35. Anjos RB. Avaliação de HPA e BTEX no solo e água subterrânea, em postos de revenda de combustíveis: estudo de caso na cidade de NatalRN [dissertação]. Natal (RN): Universidade Federal do Rio Grande do Norte; 2012.

36. Landon MK, Belitz K. Geogenic sources of benzene in aquifers used for Public Supply, California. Environ Sci Technol. 2012; 46(16):8689-97.

37. Tiburtius ERL, Peralta-Zamora P, Emmel A, Leal ES. Degradação de BTXs via processos oxidativos avançados. Química Nova. 2005;28(1):61-4.

38. Environmental Protection Agency (EPA). Ambient water quality criteria for benzene [Internet]. 1980 [cited 2014 Dec 2]. Available from: http:// water.epa.gov/scitech/swguidance/standards/upload/2001_10_12_ criteria_ambientwqc_benzene80.pdf

39. Brasil. Ministério da Saúde. Portaria $\mathrm{n}^{\circ} 2.914$, de 12 de dezembro de 2011. Dispõe sobre os procedimentos de controle e de vigilância da qualidade da água para consumo humano e seu padrão de potabilidade. Diário Oficial da União 2011; 12 dez.

40. Brasil. Conselho Nacional do Meio Ambiente. Resolução CONAMA $\mathrm{n}^{\circ}$ 396, de 3 de abril de 2008. Dispõe sobre a classificação e diretrizes ambientais para o enquadramento das águas subterrâneas e dá outras providências. Diário Oficial da União 2008; 3 abr.

41. Machado JMH, Costa DF, Cardoso LM, Arcuri A. Alternativas e processos de vigilância em saúde do trabalhador relacionados à exposição ao benzeno no Brasil. Ciênc Saúde Coletiva. 2003;8(4):913-21.

42. Costa DF. Prevenção da exposição ao benzeno no Brasil [tese]. São Paulo (SP): Universidade de São Paulo. Faculdade de Medicina; 2009.

43. Brasil. Ministério do Trabalho. Norma regulamentadora $\mathrm{n}^{\circ} 15$. Programa de Controle Médico de Saúde Ocupacional. São Paulo: Editora Atlas; 2010.

44. Brasil. Ministério do Trabalho e Emprego. Portaria $n^{\circ} 10$, de 8 de Setembro de 1994. Diário Oficial da União 1994; 12 set.

45. Brasil. Ministério do Trabalho e Emprego. Acordo e legislação sobre o benzeno. São Paulo: Fundacentro; 1995.

46. Brasil. Ministério da Saúde. Risco químico: atenção à saúde dos trabalhadores expostos ao benzeno. Brasília; Ministério da Saúde; 2006.

47. Godoi RHM, Godoi AFL, Gonçalves Junior SJ, Paralovo SL, Borillo GC, Barbosa CGG, et al. Healthy environment - indoor air quality of Brazilian elementary schools nearby petrochemical industry. Science of the Total Environment. 2013;463-464:639-46.

48. Carvalho-Oliveira R, Pozo RM, Lobo DJ, Lichtenfels AJ, MartinsJunior HA, Bustilho JO, Saiki M, Sato IM, Saldiva PH. Diesel emissions significantly influence composition and mutagenicity of ambient particles: a case study in São Paulo, Brazil. Environ Res. 2005;98(1):1-7.

49. Parreira FV, Carvalho CR, Cardeal ZL. Evaluation of indoor exposition to benzene, toluene, ethylbenzene, xylene, and styrene by passive sampling with a solid-phase microextraction device. J Chromatogr Sci. 2002;40(3):122-6.

50. Vieira AC, Zampieri RA, de Siqueira ME, Martins I, Figueiredo EC. Molecularly imprinted solid-phase extraction and high-performance liquid chromatography with ultraviolet detection for the determination of urinary trans,trans-muconic acid: a comparison with ionic exchange extraction. Analyst. 2012;137(10):2462-9.

51. Menezes M, Balbão MS, Siqueira ME, Martins I. Influência do hábito de fumar na excreção urinária do ácido trans, trans-mucônico. Rev Bras Ciênc Farm. 2008;44(3):459-64.

52. Martins I, Siqueira MEPB. Trans,trans-muconic acid in urine samples collected in three periods from benzene handling workers in a Brazilian refinery. Rev Bras Cienc Farm. 2004; 40(2):197-201.

53. Paula FCS, Silveira JN, Junqueira RG, Leite EMA. Avaliação do ácido trans, trans-mucônico urinário como biomarcador de exposição ao benzeno. Rev Saúde Pública. 2003;37(6):780-5.

54. Martins I, Siqueira MEB. Determinação do ácido trans, trans-mucônico em urina: validação de um método analítico por cromatografia líquida de alta eficiência. Rev Bras Ciênc Farm. 2002;38(2):205-13.

55. Alegretti AP, Thiesen FV, Maciel GP. Analytical method for evaluation of exposure to benzene, toluene, xylene in blood by gas chromatography preceded by solid phase microextraction. J Chromatogr B Analyt Technol Biomed Life Sci. 2004;809(1):183-7. 
56. Da Rosa JC, Fiegenbaum M, Soledar AL, Claus MS, Nunes ADS, Cardoso VV. Cytogenetic evaluation and the association with polymorphisms of the CPY1A1 and NR1I3 genes in individuals exposed to BTEX. Environ Monit Assess. 2013;185(7):5883-90.

57. Lima CSP, Lourenço GJ, Lorand-Metze I, Nascimento H, Saad STO, Costa FF. No contribution of GSTM1 and GSTT1 null genotypes to the risk of neutropenia due to benzene exposure in Southeastern Brazil. Genet Mol Biol. 2009;32(4):709-11.

58. Santiago F, Alves G, Otero UB, Tabalipa MM, Scherrer LR, Kosyakova N, et al. Monitoring of gas station attendants exposure to benzene, toluene, xylene (BTX) using three-color chromosome painting. Mol Cytogenet. 2014;7(1):15.

59. Trevisan P, da Silva JN, da Silva AP, Rosa RF, Paskulin GA, Thiesen FV, et al. Evaluation of genotoxic effects of benzene and its derivatives in workers of gas stations. Environ Monit Assess. 2014;186(4):2195-204.

60. Moro AM, Charão MF, Brucker N, Durgante J, Baierle M, Bubols G, et al. Genotoxicity and oxidative stress in gasoline station attendants. Mutat Res. 2013;754(1-2):63-70.

61. Zucchi TD, Zucchi FD, Poli P, Melo IS, Zucchi TM. A short-term test adapted to detect the genotoxic effects of environmental volatile pollutants (benzene fumes) using the filamentous fungus Aspergillus nidulans. J Environ Monit. 2005;7(6):598-602.

62. Maluf E, Hamerschlak N, Cavalcanti AB, Azevum Júnior A, Eluf-Neto J, Falcão RP, Lorand-Metze IG, et al. Incidence and risk factors of aplastic anemia in Latin American countries: the LATIN case-control study. Haematologica. 2009;94(9):1220-6.

63. Brandão MM, Rêgo MAV, Pugliese L, Clarêncio J, Bastos CM, Ferreira J, et al. Phenotype analysis of lymphocytes of workers with chronic benzene poisoning. Immunol Lett. 2005;101(1):65-70.

64. Rasera IM. Toxicidade do benzeno, fontes de contaminação e análises laboratoriais [monografia]. Novo Hamburgo (SC): Centro Universitário Feevale. Instituto de Ciências da Saúde; 2009.

65. Monks TJ, Butterworth M, Lau SS. The fate of benzene-oxide. Chem Biol Interact. 2010;184(1-2):201-6.

66. Snyder R, Hedli CC. An overview of benzene metabolism. Environ Health Perspect. 1996;104(Suppl 6):1165-71.

67. Ross D. Metabolic basis of benzene toxicity. Eur J Haematol Suppl. 1996;60:111-8.

68. Chaney AM, Carlson GP. Comparison of rat hepatic and pulmonary microsomal metabolism of benzene and the lack of benzene induced pneumotoxicity and hepatotoxicity. Toxicology. 1995;104(1-3):53-62.

69. Ross D. The role of metabolism and specific metabolites in benzene-induced toxicity: evidence and issues. J Toxicol Environ Health. 2000;61(5-6):357-72.

70. North M, Tandon VJ, Thomas R, Loguinov A, Gerlovina I, Hubbard $\mathrm{AE}$, et al. Genome-wide functional profiling reveals genes required for tolerance to benzene metabolites in yeast. PLoS One. 2011;6(8):e24205.

71. MacDonald KDD. Investigating the role of reactive oxygen species in benzoquinone-mediated dna damage and recombination in fetal hematopoietic cells [dissertação]. Ontario (Canadá): Queen's University Kingston. Department of Pharmacology and Toxicology; 2010.

72. Buthbumrung N, Mahidol C, Navasumrit P, Promvijit J, Hunsonti $\mathrm{P}$, Autrup $\mathrm{H}$, et al. Oxidative DNA damage and influence of genetic polymorphisms among urban and rural schoolchildren exposed to benzene. Chem Biol Interact. 2008;172(3):185-94.
73. Rappaport SM, Waidyanatha S, Qu Q, Shore R, Jin X, Cohen B, et al. Albumin adducts of benzene oxide and 1,4-benzoquinone as measures of human benzene metabolism. Cancer Res. 2002;62(5):1330-7.

74. Tornqvist M, Fred C, Haglund J, Helleberg H, Paulsson B, Rydberg P. Protein adducts: quantitative and qualitative aspects of their formation, analysis and applications. J Chromatogr B Analyt Technol Biomed Life Sci. 2002;778(1-2):279-308.

75. Hartwig A. The role of DNA repair in benzene- induced carcinogenesis. Chem Biol Interact. 2010;184(1-2):269-72.

76. Poirier MC. Chemical-induced DNA damage and human cancer risk. Nat Rev Cancer. 2004;4(8):630-7.

77. Snyder R. Benzene and leukemia. Int J Environ Res Public Health.. 2012;9(8):2875-93

78. McHale CM, Zhang L, Smith MT. Current understanding of the mechanism of benzene- induced leukemia in humans: implications for risk assessment. Carcinogenesis. 2012;33(2):240-52.

79. Loureiro APM, Mascio PD, Medeiros MHG. Formação de adutos exocíclicos com bases de DNA: implicações em mutagênese e carcinogênese. Quím Nova. 2002;25(5):777-93.

80. Lau SS, Kuhlman C, Bratton SB, Monks TJ. Role of hydroquinonethiol conjugates in benzene-mediated toxicity. Chem Biol Interact. 2010;184(1-2):212-7.

81. Koivisto P, Peltonen K. Analytical methods in DNA and protein adduct analysis. Anal Bioanal Chem. 2010;398(6):2563-72.

82. Funk WE, Waidyanatha S, Chaing Sh, Rappaport SM. Hemoglobin adducts of benzene oxide in neonatal and adult dried blood spots. Cancer Epidemiol Biomarkers Prev. 2008;17(8):1896-901.

83. Phillips DH. DNA adducts as markers of exposure and risk. Mut Res. 2005;577(1-2):284-92.

84. O'Connell KY, Smith MT, Dosemeci M, Hayes RB, Zhang L, Li G, et al. Non-linear production of benzene oxide-albumin adducts with human exposure to benzene. J Chromatogr B Analyt Technol Biomed Life Sci. 2002;778(1-2):367-74

85. De Palma G, Mutti A, Spatari G, Andreoli R, Mozzoni P, Carrieri M, et al. Biomarkers of effect and susceptibility to low doses of benzene. G Ital Med Lav Ergon. 2013;35(4):259-62.

86. Ross D, Zhou H. Relationships between metabolic and non-metabolic susceptibility factors in benzene toxicity. Chem Biol Interact. 2010;184(12):222-8.

87. Kim S, Lan Q, Waidyanatha S, Chanock S, Johnson BA, Vermeulen R, et al. Genetic polymorphisms and benzene metabolism in humans exposed to a wide range of air concentrations. Pharmacogenet Genomics. 2007;17(10):789-801.

88. Lan Q, Zhang L, Li G, Vermeulen R, Weinberg RS, Dosemeci M, et al. Hematotoxicity in workers exposed to low levels of benzene. Science. 2004;306(5702):1774-6.

89. Wallace LA. The Total Exposure Assessment Methodology (TEAM) Study. Washington, DC: U.S. Environmental Protection Agency; 1987.

90. Weaver VM, Buckley T, Groopman JD. Lack of specificity of trans,trans- muconic acid as a benzene biomarker after ingestion of sorbic acid-preserved foods. Cancer Epidemiol Biomarkers Prev. 2000;9(7):749-55 
91. Brugnone F, Perbellini L, Romeo L, Bianchin M, Tonello A, Pinalto G, et al. Benzene in environmental air and human blood. Int Arch Occup Environ Health.1998;71(8):554-9.

92. Augusto LGS, Freitas CM. O princípio da precaução no uso de indicadores de riscos químicos ambientais em saúde do trabalhador. Ciênc Saúde Coletiva. 1998;3(2):85-95

93. Amorim LCA. O uso dos biomarcadores na avaliação da exposição ocupacional a substâncias químicas. Rev Bras Med Trab. 2003;1(2):124-32.

94. Rappaport SM, Kim S, Thomas R, Johnson BA, Bois FY, Kupper LL. Low-dose metabolism of benzene in humans: science and obfuscation. Carcinogenesis. 2013;34(1):2-9.

95. Infante PF. The IARC october 2009 evaluation of benzene carcinogenicity was incomplete and needs to be reconsidered. Am J Ind Med. 2011;54(2):157-64.

96. Pyatt DW, Aylward LL, Hays SM. Is age an independent risk factor for chemically induced acute myelogenous leukemia in children? J Toxicol Environ Health B Crit Rev. 2007;10(5):379-400.

97. Schnatter AR, Rosamilia K, Wojcik NC. Review of the literature on benzene exposure and leukemia subtypes. Chem Biol Interact. 2005;153-154:9-21.

98. Galbraith D, Gross SA, Paustenbach D. Benzene and human health: a historical review and appraisal of associations with various diseases. Crit Rev Toxicol. 2010;40(Suppl 2):1-46.

99. Smith MT, Jones RM, Smith AH. Benzene exposure and risk of non- Hodgkin lymphoma. Cancer Epidemiol Biomarkers Prev. 2007;16(3):385-91.

100. Savitz DA, Andrews KW. Review of epidemiologic evidence on benzene and lymphatic and hematopoietic cancers. Am J Ind Med. 1997;31(3):287-95.

101. Infante PF. Benzene exposure and multiple myeloma: a detailed metaanalysis of benzene cohort studies. Ann N Y Acad Sci. 2006;1076:90-109.

102. Mandani P, Desai K, Highland H. Cytotoxic effects of benzene metabolites on human sperm function: an in vitro study. ISRN Toxicology. 2013; article ID 397524.

103. Katukam V, Kulakarni M, Syed R, Alharbi K, Naik J. Effect of benzene exposure on fertility of male workers employed in bulk drug industries. Genet Test Mol Biomarkers. 2012;16(6):592-7.

104. Xing C, Marchetti F, Li G, Weldon RH, Kurtovich E, Young S, et al. Benzene exposure near the U.S. permissible limit is associated with sperm aneuploidy. Environ Health Perspect. 2010;118(6):833-9.

105. Tunsaringkarn T, Soogarun S, Palasuwan A. Occupational exposure to benzene and changes in hematological parameters and urinary trans, trans- muconic acid. Int J Occup Environ Med. 2013;4(1):45-9.

106. American Conference of Governamental Industrial Hygienist (ACGIH). Threshold Limit Values for Chemicals Substances and Physical Agents and Biological Exposure Indices. Cincinnati, OH: ACGIH; 2003.

107. Sorensen M, Skov H, Autrup H, Hertel O, Loft S. Urban benzene exposure and oxidative DNA damage: influence of genetic polymorphisms in metabolism genes. Sci Total Environ. 2003;309(1-3):69-80.

108. Dionísio FSA, Rohlfs DB. Benzeno: dinâmica ambiental, efeitos na saúde e regulamentação [monografia]. Goiás: Pontifícia Universidade Católica de Goiás; 2013.

109. Pelallo-Martínez NA, Batres-Esquivel L, Carrizales-Yáñez L, DíazBarriga FM. Genotoxic and hematological effects in children exposed to a chemical mixture in a petrochemical area in Mexico. Arch Environ Contam Toxicol. 2014;67(1):1-8.

110. Fustinoni S, Campo L, Satta G, Campagna M, Ibba A, Tocco MG, et al. Environmental and lifestyle factors affect benzene uptake biomonitoring of residents near a petrochemical plant. Environ Int. 2012;39(1):2-7

111. Steffen C, Auclerc MF, Auvrignon A, Baruchel A, Kebaili K, Lambilliotte A, et al. Acute childhood leukaemia and environmental exposure to potential sources of benzene and other hydrocarbons; a case-control study. Occup Environ Med. 2004;61(9):773-8.

112. Brasil. Ministério do Trabalho. Norma regulamentadora $\mathrm{n}^{\circ} 7$ Segurança e medicina do trabalho. Programa de Controle Médico de Saúde Ocupacional. São Paulo: Editora Atlas; 2010.

113. Brasil. Ministério do Trabalho e Emprego. Portaria $n^{\circ} 34$, de 20 de dezembro de 2001. Diário Oficial da União 2001; 20 dez.

114. Costa MFB, Machado JMH, Moreira J, Brickus LSR. Aplicabilidade do ácido trans,trans-mucônico urinário como indicador biológico na avaliação da exposição ocupacional ao benzeno. Revista Brasileira de Toxicologia. 2000;13:63-8.

115. Costa MFB. Estudo da aplicabilidade do ácido trans,trans-mucônico urinário como indicador biológico de exposição ao benzeno [tese]. Rio de Janeiro: Escola Nacional de Saúde Pública; 2001.

116. Campagna M, Satta G, Campo L, Flore V, Ibba A, Meloni M, et al Analysis of potential influence factors on background urinary benzene concentration among a non-smoking, non-occupationally exposed general population sample. Int Arch Occup Environ Health. 2014;87(7):793-9.

117. Hoet P, De Smedt E, Ferrari M, Imbriani M, Maestri L, Negri S, et al. Evaluation of urinary biomarkers of exposure to benzene: correlation with blood benzene and influence of confounding factors. Int Arch Occup Environ Health. 2009;82(8):985-95.

118. Cocco P, Tocco MG, Ibba A, Scano L, Ennas MG, Flore C, Randaccio FS. trans,trans-muconic acid excretion in relation to environmental exposure to benzene. Int Arch Occup Environ Health. 2003;76(6):456-60.

119. Protano C, Andreoli R, Manini P, Vitali M. Urinary trans,transmuconic acid and S-phenylmercapturic acid are indicative of exposure to urban benzene pollution during childhood. Sci Total Environ. 2012;435-6:115-23.

120. Gagné S. Determination of trans,trans-muconic acid in workers' urine through ultra-performance liquid chromatography coupled to tandem mass spectrometry. Biomed Chromatogr. 2012;27(5):664-8.

121. Rekhadevi PV, Mahboob M, Rahman MF, Grover P. Determination of genetic damage and urinary metabolites in fuel filling station attendants. Environ Mol Mutagen. 2011;52(4):310-8.

122. Lovreglio P, D'Errico MN, Fustinoni S, Drago I, Barbieri A, Sabatini L, et al. Biomarkers of internal dose for the assessment of environmental exposure to benzene. J Environ Monit. 2011;13(10):2921-8.

123. Lovreglio P, Barbieri A, Carrieri M, Sabatini L, Fracasso ME, Doria D, et al. Validity of new biomarkers of internal dose for use in the biological monitoring of occupational and environmental exposure to low concentrations of benzene and toluene. Int Arch Occup Environ Health. 2010;83(3):341-56.

124.Ducos P, Berode M, Francin JM, Arnoux C, Lefèvre C. Biological monitoring of exposure to solventes using the chemical itself in urine: application to toluene. Int Arch Occup Environ Health. 2008;81(3):273-84 
125. Hopf NB, Kirkeleit J, Bratveit M, Succop P, Talaska G, Moen BE. Evaluation of exposure biomarkers in offshore workers exposed to low benzene and toluene concentrations. Int Arch Occup Environ Health. 2012;85(3):261-71.

126. Protano C, Guidotti M, Manini P, Petyx M, La Torre G, Vitali M. Benzene exposure in childhood: role of living environments and assessment of available tools. Environ Int. 2010;36(7):779-87.

127.Manini P, De Palma G, Andreoli R, Mozzoni P, Poli D, Goldoni M, et al. Occupational exposure to low levels of benzene: biomarkers of exposure and nucleic acid oxidation and their modulation by polymorphic xenobiotic metabolizing enzymes. Toxicol Lett. 2010;193(3):229-35.

128. Schettgen T, Musiol A, Alt A, Kraus T. Fast determination of urinary S-phenylmercapturic acid (S-PMA) and S-benzylmercapturic acid (S-BMA) by column-switching liquid chromatography-tandem mass spectrometry. J Chromatogr B Analyt Technol Biomed Life Sci. 2008;863(2):283-92.

129. Pieri M, Miraglia N, Acampora A, Genovese G, Soleo L, Sannolo N. Determination of urinary S-phenylmercapturic acid by liquid chromatography-tandem mass spectrometry. J Chromatogr B Analyt Technol Biomed Life Sci. 2003;795(2):347-54.

130. Farmer PB, Kaur B, Roach J, Levy L, Consonni D, Bertazzi PA, Pesatori A, et al. The use of S-phenylmercapturic acid as a biomarker in molecular epidemiology studies of benzene. Chem Biol Interact. 2005;153-4:97-102.

131. Melikian AA, Qu Q, Shore R, Li G, Li H, Jin X, et al. Personal exposure to different levels of benzene and its relationships to the urinary metabolites
S-phenylmercapturic acid and trans, trans-muconic acid. J Chromatogr B Analyt Technol Biomed Life Sci. 2002;778(1-2):211-21.

132. Ayi-Fanou L, Avogbe PH, Fayomi B, Keith G, Hountondji C, Creppy EE, et al. DNA-adducts in subjects exposed to urban air pollution by benzene and polycyclic aromatic hydrocarbons (PAHs) in Cotonou, Benin. Environ Toxicol. 2011;26(1):93-102.

133. Phillips DH, Farmer PB, Beland FA, Nath RG, Poirier MC, Reddy MV, et al. Methods of DNA adduct determination and their application to testing compounds for genotoxicity. Environ Mol Mutagen. 2000;35(3):222-33.

134.Phillips DH. On the origins and development of the ${ }^{32} \mathrm{P}$-postlabelling assay for carcinogen-DNA adducts. Cancer Letters. 2013;334(1):5-9.

135. Gouvêa AV, Cardoso MHWM, Bastos LHP, Barata-Silva C, Ortiz ND, Nóbrega AW, et al. Avaliação da contaminação de resíduos de agrotóxicos em amostras de soja utilizando o método quechers-acetato com a técnica de cromatografia líquida acoplada à espectrometria de massas sequencial. Revista do Instituto Adolfo Lutz. 2014;73.

136. Atkinson TJ. A review of the role of benzene metabolites and mechanisms in malignant transformation: summative evidence for a lack of research in nonmyelogenous cancer types. Int J Hyg Environ Health. 2009:212(1):1-10.

137. Hartwig A. The role of DNA repair in benzene-induced carcinogenesis. Chem Biol Interact. 2010;184(1-2):269-72.

Recebido em: 01/10/2014

Aprovado em: 12/12/2014 